\title{
A New Concept of Instantaneous Whirling Speed for Cracked Rotor's Axis Orbit
}

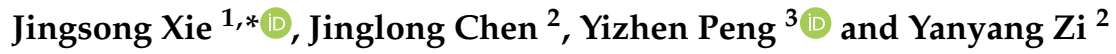 \\ 1 School of Traffic and Transportation Engineering, Central South University, Changsha 410075, China \\ 2 State Key Laboratory for Manufacturing Systems Engineering, Xi'an Jiaotong University, \\ Xi'an 710049, China; jlstrive2008@mail.xjtu.edu.cn (J.C.); ziyy@mail.xjtu.edu.cn (Y.Z.) \\ 3 College of Mechanical Engineering, Chongqing University, Choangqing 400044, China; pengyz@cqu.edu.cn \\ * Correspondence: jingsongxie@foxmail.com
}

Received: 24 August 2019; Accepted: 24 September 2019; Published: 2 October 2019

check for updates

\section{Featured Application: This work provides a potential application for distinguishing normal and cracked rotor systems.}

\begin{abstract}
At present, the axis orbit (whirling) and the instantaneous angular speed (spinning) are important symptoms in the condition monitoring of rotor systems. However, because of the lack of research of the transient characteristics of axis orbit within a whirl cycle, the axis orbit cannot reflect the instantaneous characteristics of the rotation during one whirling cycle like the instantaneous angular speed. Therefore, in this paper, a new concept of instantaneous whirling speed of axis orbit within a whirling cycle is proposed and defined. In addition, the transient characteristics of instantaneous whirling speed are studied. Meanwhile, the response mechanisms are qualitative analyzed through the study of the work of the additional stiffness excitation and the conversion relationship between the kinetic energy and the potential energy. Then, the minimum of the relative instantaneous whirling speed (RWS) is proposed as a potential monitoring index for crack severity. The instantaneous whirling speed is a new attribute of axis orbit and a new perspective for the vibration analysis of cracked rotors. The addition of this new attribute significantly increases the effect of axis orbit for distinguishing normal and cracked rotors. The new analysis perspective and the new diagnosis index are potential supplements for crack diagnosis.
\end{abstract}

Keywords: axis orbit; instantaneous whirling speed; response mechanism; crack diagnosis

\section{Introduction}

Rotor system is an important part of the rotating machinery which is widely used in the area of aerospace, rail transportation, and energy fields. However, because of poor working condition and the cyclic loading, fatigue cracks often occur in the position which has initial damages or stress concentration. Accidents caused by crack growth are catastrophic, thus the monitoring of cracks is widely considered. The research of the vibration characteristic and monitoring index can provide significant references for crack diagnosis.

Scholars have carried out extensive research on rotor crack diagnosis. The study of the breathing mechanism promotes the further understanding of crack mechanical behavior [1]. The vibration analysis provides optimal indicators for crack detection [2] and harmonic component extraction obtains more fault information [3,4]. In addition, model updating method [5], modal state observer method [6], and modal force identification method [7] for identifying cracks have also been deeply studied. Meanwhile, the feature extraction method for acoustic signals [8], the classification methods for motor faults [9], and the sensor fusion approach for acoustic, electric, and vibration signals [10] 
can provide important reference for rotor crack diagnosis. However, different methods have their own advantages and applicable objects. Axis orbits and instantaneous angular speeds are the two important diagnostic criteria for crack diagnosis of shaft.

Axis orbits can be obtained by two vertical displacement sensors and have important values for the condition monitoring of rotor systems. Wang [11] used axis orbits to investigate the stability of a twin-crew refrigeration compressor. Axis orbits are also used as information source to identify the torque load of rotor system and to balance the rotor system [12,13]. For the diagnosis of rotor cracks, Meng [14] found that the axis orbit for each harmonic component is an ellipse, the shape and orientation orbit of which depend on the crack size. Sinou [15] indicated that both of the orbit evolution at half of the first critical speed and the magnitude of the response at the first critical speed and at half of the first critical speed may be considered as the unique characteristics of the system with a breathing crack. Cao [16] demonstrated that the distortion of the orbit at the $1 / 2$ first critical speed could be considered as one of the most practical indicators of the presence of a transversal crack. Sinha [17] presented an experimental study on the axis orbit response for different rotor-related faults. Yan [18] studied the whirl orbits evolution around the 1/3 subcritical speed zone and showed that two inner loops appear in the whirl orbits of cracked rotor. Ling [19] presented the number and orientation changes of inner loops during the subcritical speed region of rotor system with crack. Shudeifat [20] discovered new backward whirl zones which are affected by the crack damage in the shaft. The above reviews show that axis orbit is a key characteristic in rotor system monitoring and provide important references for crack identification. However, axis orbit only reflects the trajectory information of a whirling cycle and ignored the instantaneous characteristics of the rotation during one whirling cycle.

The instantaneous characteristic during a whirling cycle and a spinning cycle contains a lot of fault characteristic information. Sinha [21] measured the shaft instantaneous angular speed (IAS) and they showed a distinct difference between the healthy and the faulty blade conditions. Moustafa [22] indicated that instantaneous angular speed is strictly synchronized to shaft rotation and much less dependent on the transfer path between the defect and the sensor. They also showed that IAS measurement is a promising tool for health monitoring of very low speed machines. Zhao [23] proposed a Kurtosis-guided local polynomial differentiator to estimate the instantaneous angular speed and applied it to the health monitoring of planetary gearbox. Zhang $[24,25]$ used instantaneous angular speed for the fault diagnosis of gearbox and multistage gearbox. IAS is also used for the monitoring of bearing defects and gearbox faults in wind turbines [26,27]. Basic signal processing techniques is also introduced in order to analyze the shape of rotating speed fluctuations [28]. The above reviews show that instantaneous angular speed reflects the characteristics of the rotation speed of the rotor system in a rotation cycle and provides abundant diagnostic information for rotor system faults.

To sum up, axis orbits and instantaneous angular speeds are from two different perspectives to provide methods for fault diagnosis. The axis orbit describes the whirling of the rotor system; however, the instantaneous angular speed describes the spinning of the rotor system. The axis orbit contains the amplitude and phase information of the two directions' vibration response, and has important reference values for crack diagnosis. However, the axis orbit can only reflect the characteristics of the rotor in a whole whirling cycle. At the same time, it cannot reflect the instantaneous characteristics of the rotation during one whirling cycle like the instantaneous angular speed. At some special cases, if only the morphological characteristics of the axis orbit are used, it is easy to miss the diagnosis of cracks.

Therefore, in this paper, the instantaneous whirling speed of axis orbit within a whirling cycle is defined and studied by a Jeffcott rotor model. Moreover, the relationship between the breathing effect of the crack and the transient variation characteristics of the RWS is studied. Section 2 introduces the dynamic modeling processes. Section 3 introduces the definition of instantaneous whirling speed. Section 4 explains the mechanism of the transient characteristic of whirling speed through the study of the work of the additional stiffness excitation and the conversion relationship between the kinetic 
energy and the potential energy. In Section 5, the minimum of the relative whirling speed is proposed as a potential monitoring index for crack severity.

\section{Nonlinear Dynamic Model of a Cracked Rotor}

The dynamic model adopted in this paper has been developed in our recent publication $[29,30]$. In Figure 1, oxy is a fixed coordinate system, $L$ is the length of the shaft, and $z_{\mathrm{c}}$ is the $\mathrm{z}$-coordinate of the crack position with respect to the $o-x y z$ reference system, and in this paper $z_{\mathrm{c}}=L / 2 . o^{\prime} x^{\prime} y^{\prime}$ is a rotating coordinate system, $\overrightarrow{o^{\prime} N}$ is the normal direction of the crack tip, and $H$ is a horizontal reference axis. $o_{\mathrm{C}}$ is the center of mass, $e_{\mathrm{C}}$ is the eccentric distance, and $\beta$ is the imbalance orientation angle. $\theta$ is a rotor spin angle, $\varphi$ is a whirling angle of reference frames $o^{\prime} x^{\prime} y^{\prime}$, and $\psi=\theta-\varphi$ is a rotation-whirling difference angle, and $d$ is the absolute depth of cracks.

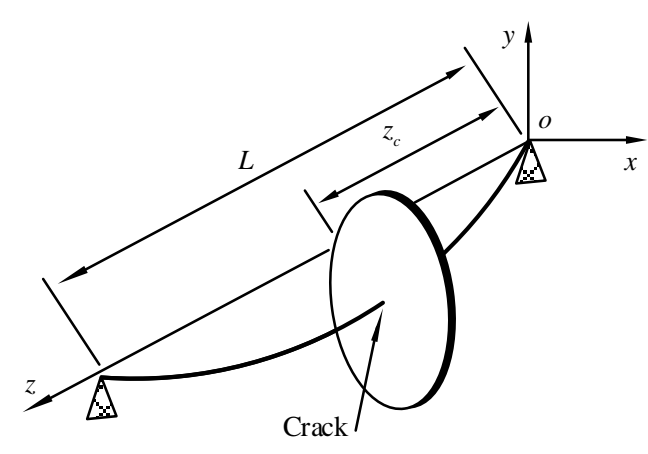

(a)

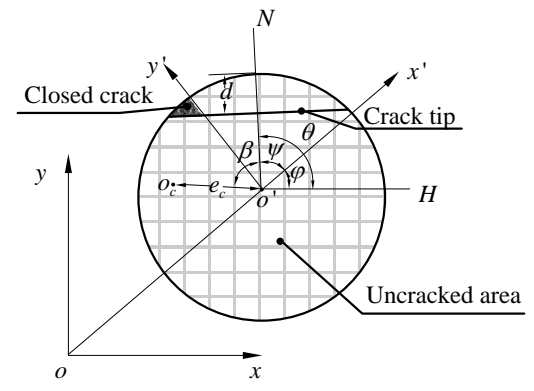

(b)

Figure 1. Schematic diagram of rotor system: (a) The Jeffcott rotor with a transverse crack, (b) schematic diagram of the cracked cross section.

The general equations of motion of a cracked Jeffcott rotor can be obtained:

$$
\begin{aligned}
& {\left[\begin{array}{cc}
m & 0 \\
0 & m
\end{array}\right]\left[\begin{array}{l}
\ddot{x} \\
\ddot{y}
\end{array}\right]+\left[\begin{array}{cc}
c & 0 \\
0 & c
\end{array}\right]\left[\begin{array}{l}
\dot{x} \\
\dot{y}
\end{array}\right]+\left[\begin{array}{cc}
k_{x}(x, y, t) & k_{x y}(x, y, t) \\
k_{x y}(x, y, t) & k_{y}(x, y, t)
\end{array}\right]\left[\begin{array}{l}
x \\
y
\end{array}\right]} \\
& =m e_{c}\left[\begin{array}{c}
\dot{\theta}^{2} \cos (\theta+\beta)+\ddot{\theta} \sin (\theta+\beta) \\
\dot{\theta}^{2} \sin (\theta+\beta)-\ddot{\theta} \cos (\theta+\beta)
\end{array}\right]-\left[\begin{array}{c}
0 \\
m g
\end{array}\right]
\end{aligned}
$$

where $\ddot{\theta}$ is the angular acceleration, $\dot{\theta}$ is the angular velocity. $k_{\mathrm{x}}, k_{\mathrm{y}}$, and $k_{\mathrm{xy}}$ are breathing stiffnesses in the fixed coordinate system $o x y$, and they can be obtained from the stiffnesses $k_{\mathrm{x}^{*}}, k_{\mathrm{y}^{*}}$, and $k_{\mathrm{x}^{*} \mathrm{y}^{*}}$ in the rotational coordinate system $o^{\prime} x^{\prime} y^{\prime}$ by Equation (2), and the stiffness expressions can be referred to citation [20].

$$
\left[\begin{array}{c}
k_{x} \\
k_{y} \\
k_{x y}
\end{array}\right]=\left[\begin{array}{ccc}
\cos ^{2}(\varphi) & \sin ^{2}(\varphi) & -\sin (2 \varphi) \\
\sin ^{2}(\varphi) & \cos ^{2}(\varphi) & \sin (2 \varphi) \\
\sin (\varphi) \cos (\varphi) & -\sin (\varphi) \cos (\varphi) & \cos (2 \varphi)
\end{array}\right] \bullet\left[\begin{array}{c}
k_{x^{*}} \\
k_{y^{*}} \\
k_{x^{*} y^{*}}
\end{array}\right]
$$

\section{The Definition of Instantaneous Whirling Speed}

The dynamic equation, Equation (1), is solved in the parameter $e=0.05, \xi=0.006, \beta=90^{\circ}, \lambda=0.7$, $\mu=0$ and $\mu=0.2$. The axis orbits of normal and cracked rotors are compared in Figure 2.

It can be seen that the normal rotor's axis orbit is a standard circular trajectory, and the cracked rotor's axis orbit is approximately a circular trajectory. It is shown that the axis orbit of the cracked rotor may be very similar to that of the normal rotor under the condition of certain system parameters. 
At this special time, if only the morphological characteristics of the axis orbit are used, it is easy to miss the diagnosis of cracks.

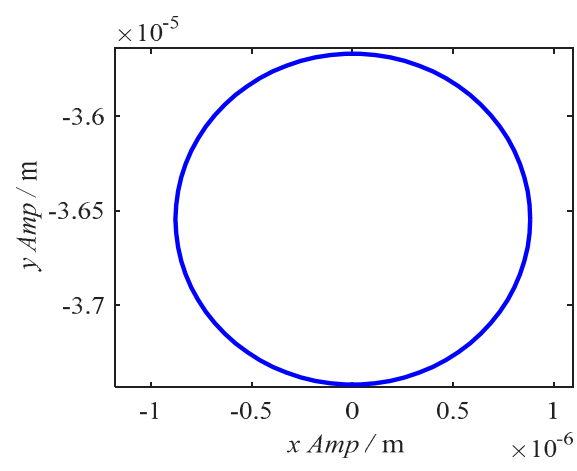

(a)

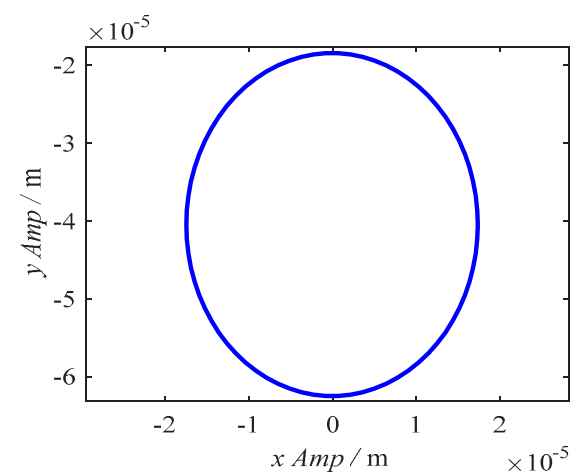

(b)

Figure 2. The axis orbits of normal and cracked rotors: (a) $\mu=0,(\mathbf{b}) \mu=0.2$.

In order to increase the effect of axis orbit for distinguishing normal and cracked rotor, the new attribute (instantaneous whirling speed) are given to axis orbit, as shown in Figures 3 and 4.

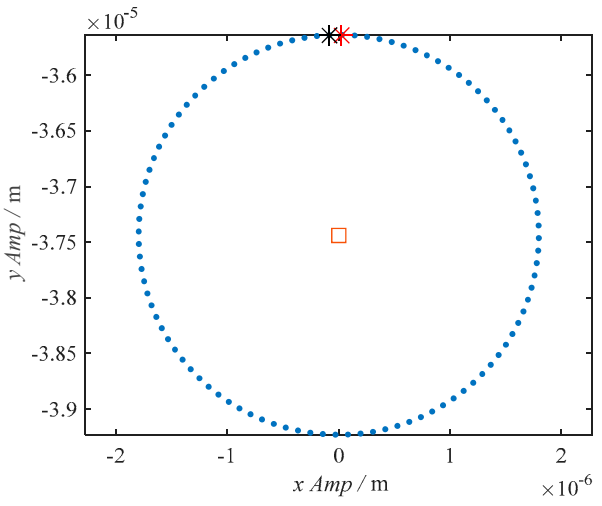

(a)

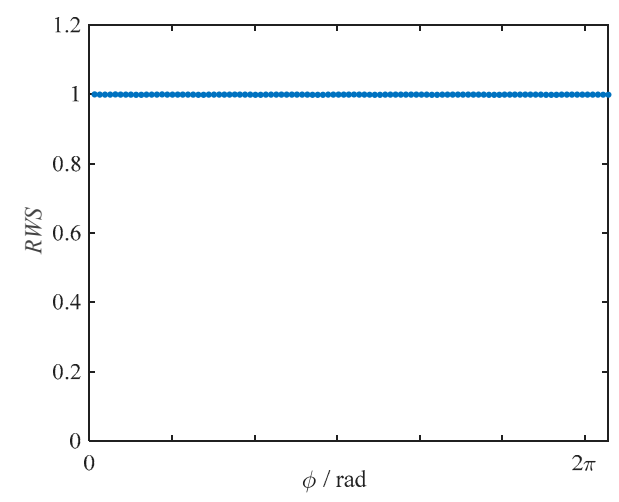

(b)

Figure 3. Steady state vibration response of normal system at $\mu=0$ : (a) discrete axis orbit, (b) relative whirling speed.

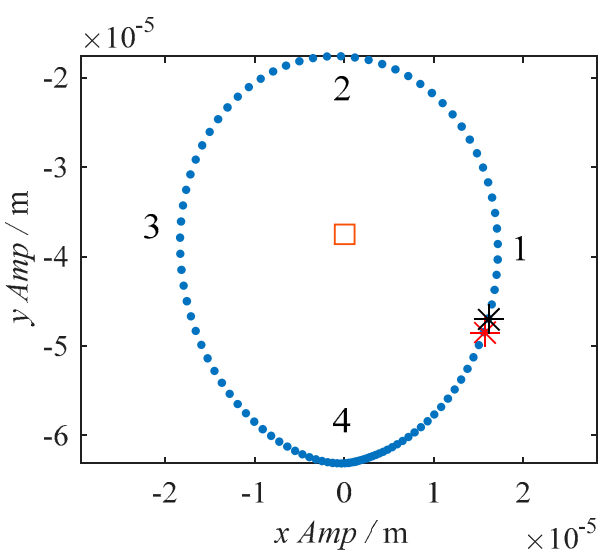

(a)

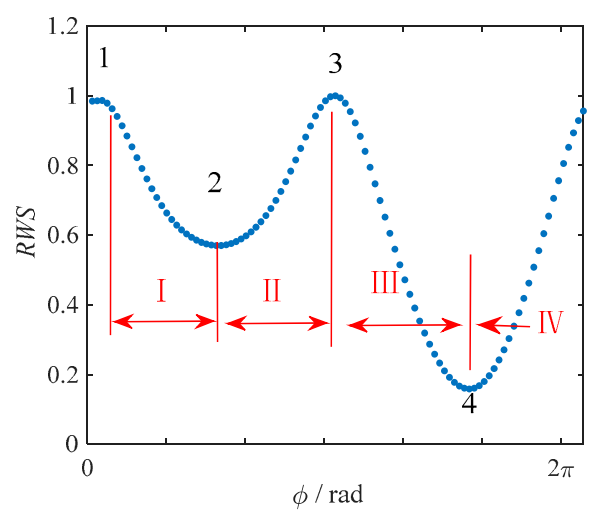

(b)

Figure 4. Steady state vibration response of cracked system at $\mu=0.2$ : (a) discrete axis orbit, (b) relative whirling speed. 
The plot diagram is shown in Figure 5. First, the vibration signal should be obtained at equal intervals. Then, the sampling points during a whirling cycle in the X-direction and Y-direction can construct a discrete axis orbit, as shown in Figures $3 \mathrm{a}$ and $4 \mathrm{a}$. After that, the whirling center can be obtained, that is the square " $\square$ " in Figures 3a and 4a. Next, the whirling center is set as the origin of the polar coordinates and the angle differences between the two adjacent sampling points are calculated. The angle difference is defined as the instantaneous whirling speed. Finally, the relative instantaneous whirling speed (RWS) is defined as the ratio of the instantaneous whirling speed to its maximum value and the RWS within a whirling cycle can be obtained, as shown in Figures $3 \mathrm{~b}$ and $4 \mathrm{~b}$.

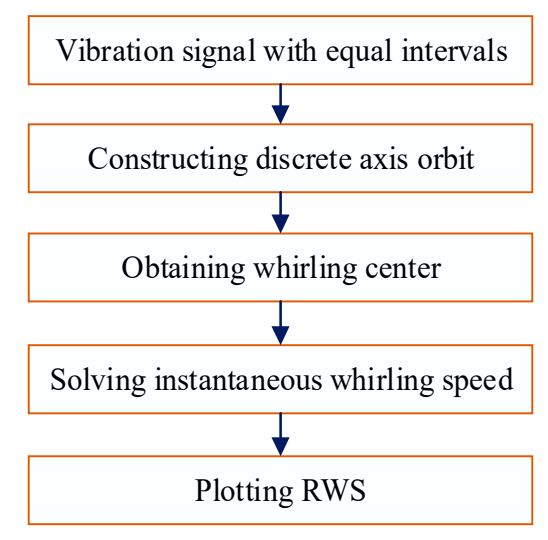

Figure 5. The plot diagram of relative instantaneous whirling speed (RWS).

Figure 3a is a discrete axis orbit which is composed of equal time interval sampling points in a whirling cycle. As it can be seen from Figure 3 a that the sampling points are uniformly distributed, indicating that the whirling angles are equal in the same time interval when $\mu=0$. Figure $3 \mathrm{~b}$ is the RWS within a whirling cycle $(0 \leq \varphi \leq 2 \pi)$. In Figure $3 b$, it can be seen that the RWS of a normal rotor system is constant.

The discrete axis orbit and RWS when $\mu=0.2$ are shown in Figure 4. In Figure 4a, it can be seen that the distribution of the sampling points in the discrete axis orbit of the cracked system is extremely uneven, and the sampling point is very dense near the position 4 . In Figure $4 \mathrm{~b}$, it has four fluctuations in the RWS in a whirling cycle. At position 1, RWS is at the local maximum value. Then RWS decreases from position 1 to position 2, reached the local minimum value at position 2 . After that, RWS increases from position 2 to position 3, reached the local maximum value at position 3 . From position 3 to position 4, RWS decreases again, and the minimum value occurs at position 4 . The RWS varies transiently in a whirling cycle.

The above analysis shows that the addition of this new attribute significantly increases the effect of axis orbit for distinguishing normal and cracked states of rotor systems.

In order to study the application effects of RWS in experimental data, the vibration response test of a rotor system is carried out on the Bently KR4 Rotor Test Rig. The parameters of the experiment are the same as that of [30]. As showed in Figure 6, the rotor test rig mainly includes speed controller, motor, shaft, and base. The data acquisition equipment mainly includes eddy current displacement probe, signal regulator, and DAS (data acquisition system). The controller supplies power to the motor and controls the speed of the motor. The displacement probe collects the lateral vibration signal of the shaft, and is connected with DAS through the signal regulator.

The displacement signals in two directions ( $x$ and $y$ ) are acquired through the displacement probes, and the curves of RWS are plotted according the diagram in Figure 5. As shown in Figure 7, the RWS curve of the system with no rotor cracks (Figure 7a) fluctuates in a small range but the RWS curve of the system with rotor cracks (Figure $7 b$ ) fluctuates in a wide range. The RWS shows distinguished differences between normal and cracked rotors and that is qualitatively consistent with the simulation results as shown in Figures $3 \mathrm{~b}$ and $4 \mathrm{~b}$. On the other hand, the real rotor system is not an ideal normal 
system and has many differences with the system simulated by the dynamic model, suggesting that the RWS of experimental data is quantitative different with that of the simulated system. The RWS of a normal real system is not a constant like that shown in Figure $3 \mathrm{~b}$ but fluctuates in a small range.

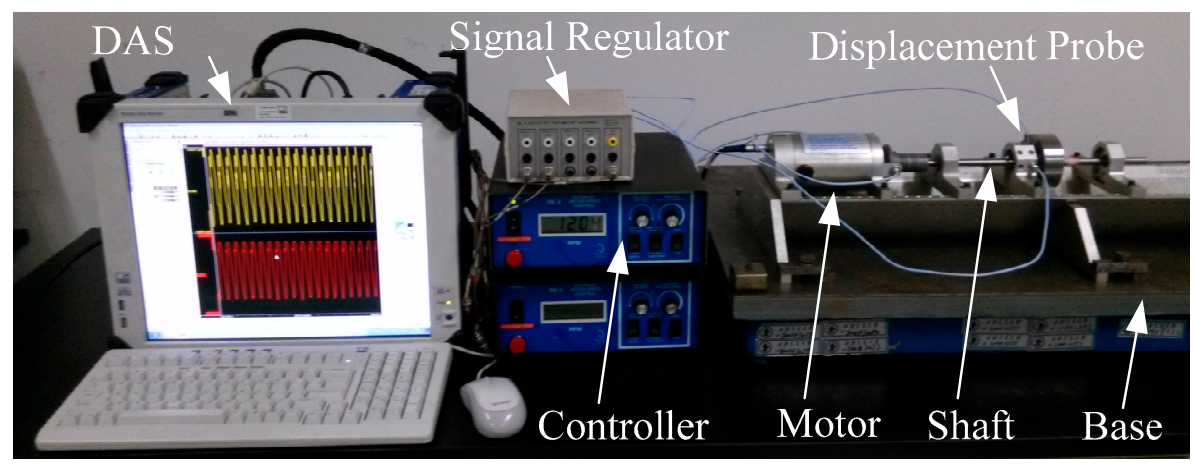

Figure 6. Bently KR4 Rotor Test Rig and data acquisition system.

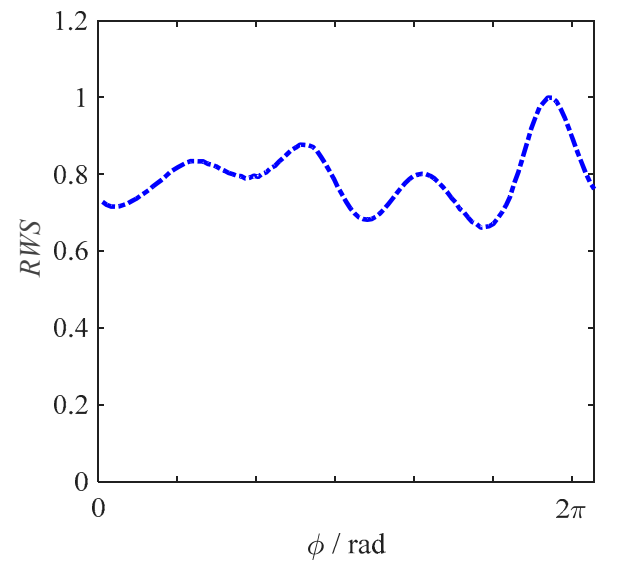

(a)

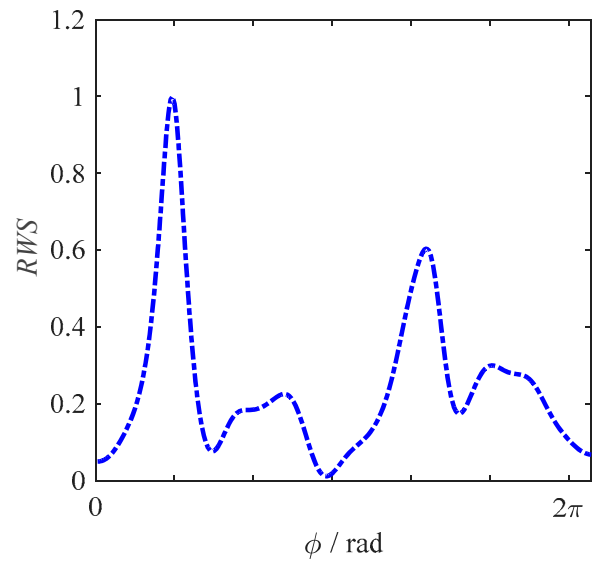

(b)

Figure 7. Comparison of RWS: (a) no crack, (b) with crack.

The comparison results show that RWS can distinguish the normal and cracked states of real rotor systems. However, real rotor systems inevitably exhibit a certain extent of compound faults, such as misalignment, oil whirl, rubbing, and other faults, which may lead to the confusion of instantaneous whirl characteristics.

\section{The Qualitative Mechanism Explanation}

To further understand the cause of this transient characteristic, this section studies the relationship between the breathing effect of the crack and the transient variation characteristics of the RWS with regard to the work of the additional stiffness excitation.

First, the line speed is introduced as the intermediate state variable. The whirling speed can be decomposed into the linear speed $L S_{x}$ and $L S_{y}$ along the X-direction and Y-direction respectively. The line speeds of the normal rotor system and the cracked rotor system are shown in Figure 8. In Figure $8 \mathrm{a}$, it can be seen that the line speeds $L S_{x}$ and $L S_{y}$ of the normal rotor are standard sine curves, and there is a $90^{\circ}$ phase difference between these two curves. Therefore, the whirling speed of the synthetic motion is a constant, as shown in Figure 3b. However, in Figure 8b, the line speeds of the cracked system are not the standard sine curve anymore. At position 4 , the line speeds $L S_{x}$ and $L S_{y}$ are close to 0 . So, at this time, the whirling speed of the synthetic motion reaches the minimum value, as shown in Figure 4b. 


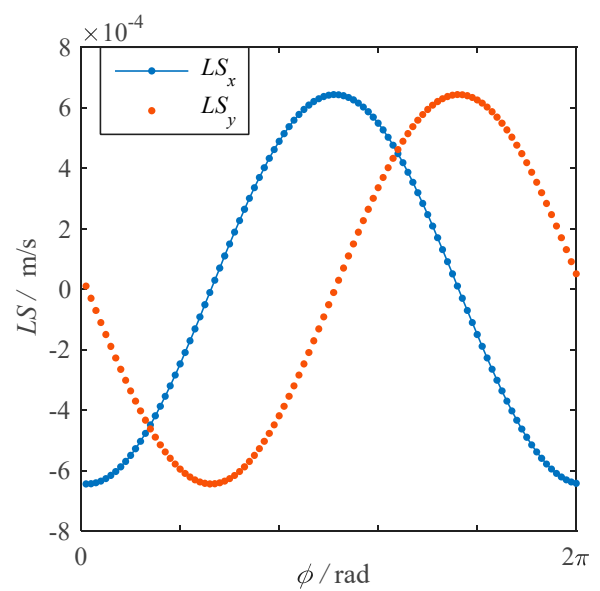

(a)

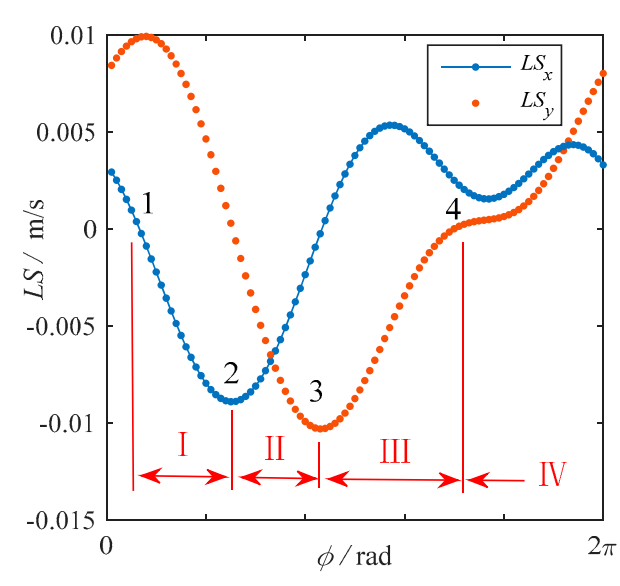

(b)

Figure 8. Line speed curves: (a) normal system, (b) cracked system.

In the steady state response of forced vibrations, the line speeds are mainly controlled by the mutual transformations of the kinetic energy and the potential energy. However, in the cracked rotor system, the non-uniform work of the additional stiffness excitation leads to the distortions of the line speed curves. In Figure $4 \mathrm{~b}$, it can be seen that the RWS has two maxima and two minima. The change mechanism of these four special positions will be analyzed in the following part.

Equation (1) can be transformed into Equation (3):

$$
\begin{aligned}
& {\left[\begin{array}{cc}
m & 0 \\
0 & m
\end{array}\right]\left[\begin{array}{l}
\ddot{x} \\
\ddot{y}
\end{array}\right]+\left[\begin{array}{ll}
c & 0 \\
0 & c
\end{array}\right]\left[\begin{array}{c}
\dot{x} \\
\dot{y}
\end{array}\right]+\left[\begin{array}{cc}
k & 0 \\
0 & k
\end{array}\right]\left[\begin{array}{l}
x \\
y
\end{array}\right]} \\
& =m e \omega^{2}\left[\begin{array}{c}
\cos (\theta+\beta) \\
\sin (\theta+\beta)
\end{array}\right]-\left[\begin{array}{c}
0 \\
m g
\end{array}\right]+\left[\begin{array}{cc}
k-k_{x}(x, y, t) & -k_{x y}(x, y, t) \\
-k_{x y}(x, y, t) & k-k_{y}(x, y, t)
\end{array}\right]\left[\begin{array}{l}
x \\
y
\end{array}\right]
\end{aligned}
$$

Compared to the normal rotor system, additional stiffness excitation forces of cracked rotor system are shown in Equations (4) and (5):

$$
\begin{aligned}
& F_{X}=F_{x}+F_{x y}=\left(k-k_{x}(x, y, t)\right) x-k_{x y}(x, y, t) y \\
& F_{Y}=F_{y}+F_{y x}=\left(k-k_{y}(x, y, t)\right) y-k_{x y}(x, y, t) x
\end{aligned}
$$

Figure 9 a shows the curves of the additional stiffness excitation forces $F_{X}$ and $F_{Y}$ within a whirling cycle. In Figure $9 \mathrm{~b}, P_{x}$ and $P_{y}$ are the instantaneous power of the additional stiffness excitation forces.

At position 1, from Figure $8 \mathrm{~b}$ we can see that the line speed $L S_{x}$ close to 0 , and the line speed $L S_{y}$ reaches the maximum value at this time. Therefore, in Figure $4 \mathrm{~b}$, the relative whirling speed of the synthetic motion closes to 1 . In this paper, position 1 is used as the reference position of relative whirling speed.

From position 1 to position 2 (process I), as shown in Figure 9a, the additional stiffness excitation forces are close to 0 . Therefore, in Figure $9 b$, the instantaneous powers of additional stiffness excitation forces are close to 0 . Therefore, the linear speeds are determined by the conversions of the kinetic energy and potential energy. It can be known from Figure $4 a$ that the kinetic energy is turned into the potential energy in Y-direction during this process, and the line speed $L S_{y}$ is close to 0 in the end. On the other hand, in X-direction, the potential energy is turned into the kinetic energy, and the line speed $L S_{x}$ reaches the negative maximum value in the end which has been shown in Figure $8 \mathrm{~b}$. However, the maximum value of the line speed in the $\mathrm{X}$-direction is less than that in the Y-direction. Therefore, at position 2, the RWS of the synthetic motion is less than that at the reference position 1 , thus the first minimum value appears in Figure $4 \mathrm{~b}$. 


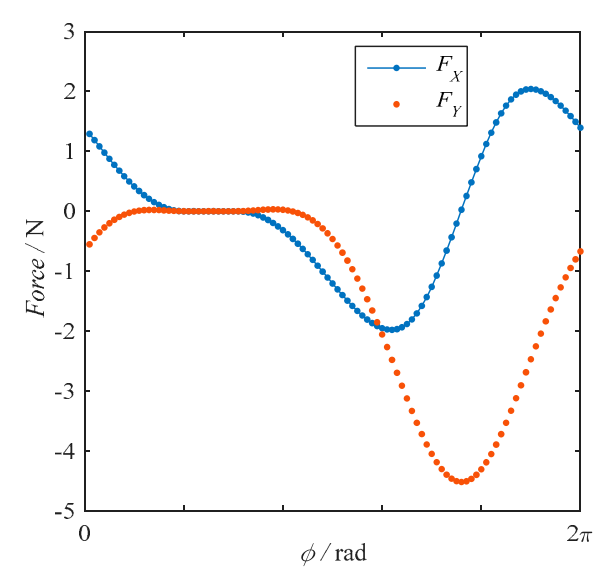

(a)

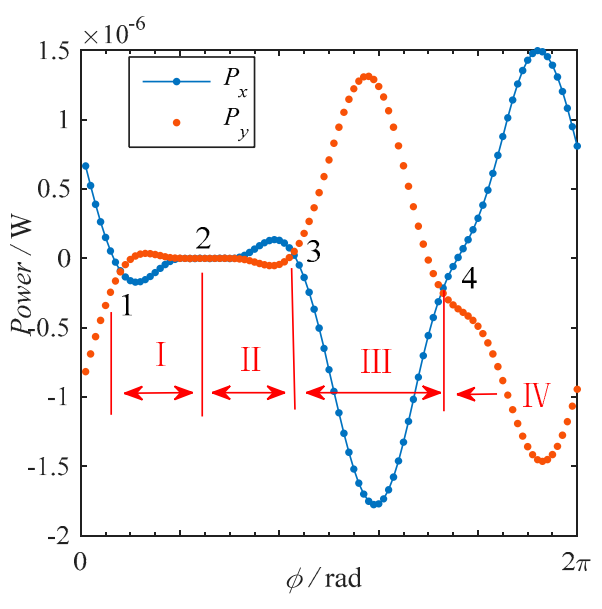

(b)

Figure 9. The additional stiffness excitation curves: (a) additional stiffness excitation forces, (b) the instantaneous power of the excitation forces.

From position 2 to position 3 (process II), it can be known from Figure 4a, the potential energy is turned into the kinetic energy in Y-direction, and the line speed $L S_{y}$ reaches the negative maximum value. In X-direction, the kinetic energy is turned into the potential energy, and the line speed $L S_{x}$ is close to 0 in the end, which has been shown in Figure $8 \mathrm{~b}$. However, the maximum value of the line speed in Y-direction is larger than that in the X-direction. Therefore, at position 3, the second maximum value of RWS of the synthetic motion appears in Figure $4 \mathrm{~b}$.

From position 3 to position 4 (process III), the line speed in Y-direction tends to be 0 and the line speed in X-direction tends to be the positive maximum value. However, as it is shown in Figure $9 \mathrm{~b}$, at this time the additional stiffness excitations do negative work in the X-direction, which prevents the line speed from following the normal change rule, and the line speed $L S_{x}$ increases at the beginning and then decreases, as it is shown in Figure 8b. On the other hand, the additional stiffness excitations do positive work in Y-direction, and the total power is less than that in X-direction. Therefore, the distortion of line speed $L S_{y}$ is not significant. Eventually, this leads to the RWS of the synthesis motion to reach the minimum value in position 4 , as shown in Figure $4 \mathrm{~b}$.

From position 4 to position 1 (process IV), it should be that the line speed in Y-direction tends to be the positive maximum value and the line speed in X-direction tends to be 0 . However, as shown in Figure $9 \mathrm{~b}$, the additional stiffness excitation do positive work in X-direction at this time. This causes the line speed $L S_{x}$ to increase at the beginning and then decrease, as shown in Figure 8b. On the other hand, the additional stiffness excitations do negative work in Y-direction, and the total power is less than that in the X-direction. Therefore, the distortion of line speed $L S_{y}$ is not particularly significant except the slow increasing speed of $L S_{y}$, as shown in Figure 8b.

The above qualitative analysis shows that the work of the additional stiffness excitations affects the normal transformation rule between the kinetic energy and the potential energy of the rotor system, resulting in the distortion of the line speed and finally making the relative whirling speed which is synthetized by the line speed vary transiently. The explanation of transient characteristics can deepen the understanding of the dynamic characteristics of the cracked rotors.

\section{RWS Varies with the Crack Depths}

The above research shows that the RWS is closely related to the breathing effect, and the breathing characteristic of the stiffness is related to the crack depths. Therefore, this section studies the variation characteristics of the RWS with the crack depths.

Figure 10 is the relative whirling speed curves for four different crack depths. The system parameters are $e=0.05, \xi=0.006, \beta=0, \lambda=1$.2. In Figure 10, it can be seen that with the increase of 
the crack depths, the two minima of the RWS appear to be decreasing. That means the fluctuations of the line speeds which are affected by the work of the additional stiffness excitations are more significant. The specific performances are shown in Figure 11.

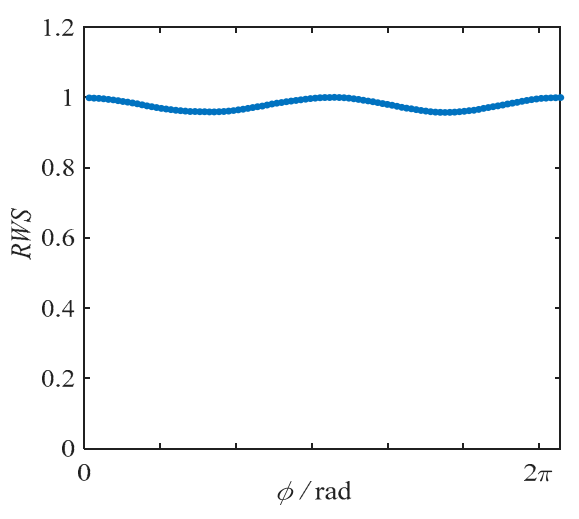

(a)

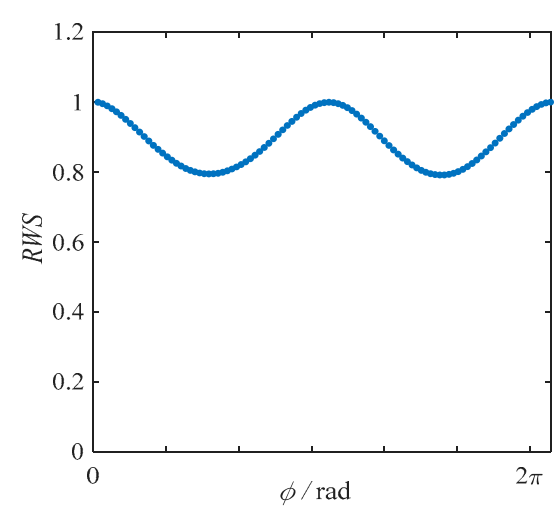

(c)

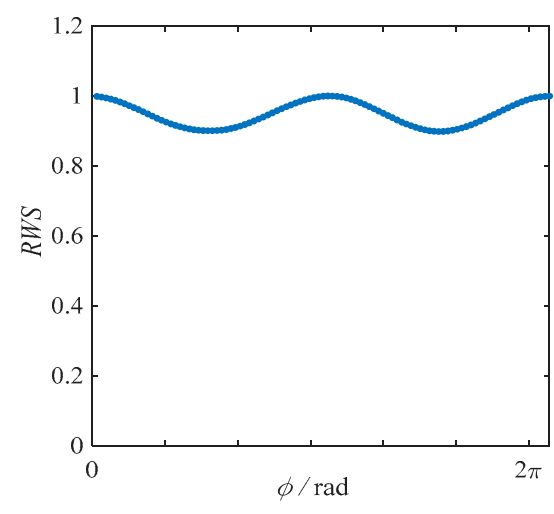

(b)

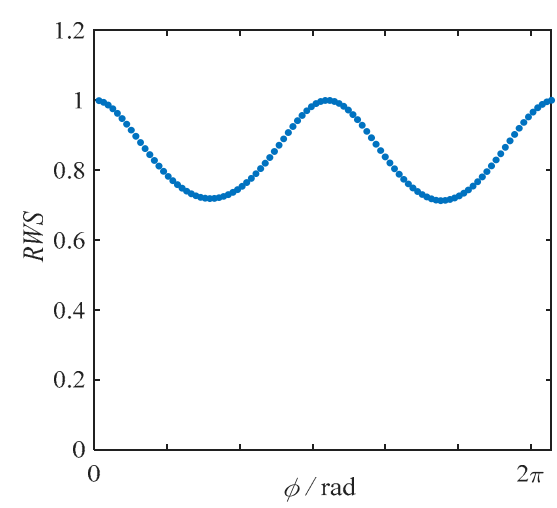

(d)

Figure 10. RWS for four crack depths: (a) $\mu=0.05$, (b) $\mu=0.1$, (c) $\mu=0.2$, (d) $\mu=0.3$.

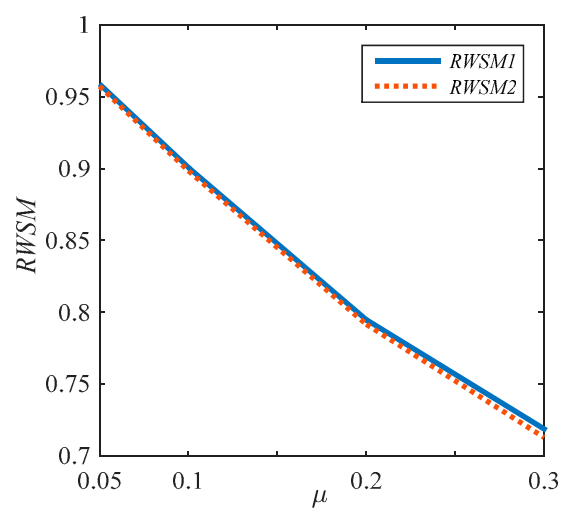

Figure 11. The trends of the two minima of RWS with the crack depths.

Figure 11 is the variation trend of the two minima of RWS (RWSM1, RWSM2) with the crack depths. As shown in Figure 11, the two minima decrease linearly with the increase of the crack depth. Therefore, the minimum of RWS (RWSM) can be a possible reference index for monitoring the severity of the crack. 


\section{Conclusions}

In this paper, a new concept of instantaneous whirling speed of axis orbit is defined and studied by a Jeffcott rotor model. The instantaneous whirling speed is a new attribute of axis orbit and a new perspective for the vibration analysis of cracked rotors. The addition of this new attribute significantly increases the effect of axis orbit for distinguishing normal and cracked rotor systems.

The characteristic analysis shows that the relative whirling speed (RWS) of a cracked rotor system varies transiently and appears two maxima and two minima in a whirling cycle. The mechanism qualitative analysis shows that the transient variation of the RWS is caused by the influence of the work of the additional stiffness excitation on the normal conversion between kinetic energy and potential energy. In addition, the minimum value of the RWS decreases linearly with the increase of the crack depths, which can be a potential monitoring index for the severity of cracks.

The explanation of the transient characteristics of axis orbit can increase the understanding of the dynamic characteristics of cracked rotors. The new analysis perspective and the new diagnosis index are potential supplements to the crack diagnosis.

As we all know, most diagnostic methods and indicators have their applicable conditions or limitations, and so do the methods in this paper. First, the instantaneous whirling speed is a new additional attribute of axis orbit, thus this index is effective for steady-state rotor systems; hence, it is difficult to obtain the approximate circular axis orbit for unsteady rotor systems. Second, when compound faults exist, such as misalignment, oil whirl, rubbing, and other faults, these may lead to the confusion of instantaneous whirl characteristics, resulting in misdiagnosis of crack faults. In view of this, more types of diagnostic indicators should be studied to complement each other and improve the accuracy of the crack diagnosis.

Author Contributions: Conceptualization, J.X.; methodology, J.X.; formal analysis, Y.P.; investigation, J.X.; writing_-original draft preparation, J.C.; project administration, Y.Z.; funding acquisition, J.X., Y.P., and Y.Z.

Funding: This work was funded by the National Key Research and Development Program of China (No. 2017YFC0805701), the National Natural Science Foundation of China (No. 51,905,054), the Scientific Research Starting Foundation of Central South University (No. 202,044,013).

Conflicts of Interest: The authors declare no conflict of interest.

\section{References}

1. Zheng, Z.; Xie, Y.; Zhang, D.; Zhu, F. Numerical investigation on the nonlinear dynamics of a breathing cracked rotor supported by flexible bearings. Proc. Inst. Mech. Eng. Part C J. Mech. Eng. Sci. 2019, 233, 6815-6826. [CrossRef]

2. Yang, Y.; Xia, W.; Han, J.; Song, Y.; Wang, J.; Dai, Y. Vibration analysis for tooth crack detection in a spur gear system with clearance nonlinearity. Int. J. Mech. Sci. 2019, 157-158, 648-661. [CrossRef]

3. Wu, J.; Zhang, X.; Li, B. A study on vibration component separation of a rotor system during startup and its application in fault diagnosis. Meas. Sci. Technol. 2019, 30, 095104. [CrossRef]

4. Xie, J.; Cheng, W.; Zi, Y.; Zhang, M. Phase-based spectrum analysis method for identifying weak harmonics. J. Vib. Control 2018, 24, 5585-5596. [CrossRef]

5. Lu, Z.; Lv, Y.; Ouyang, H. A Super-harmonic feature based updating method for crack identification in rotors using a kriging surrogate model. Appl. Sci. 2019, 9, 2428. [CrossRef]

6. Leao, L.S.; Cavalini, A., Jr.; Morais, T.S.; Melo, G.P.; Steffen, V., Jr. Fault detection in rotating machinery by using the modal state observer approach. J. Sound Vib. 2019, 458, 123-142. [CrossRef]

7. Rotating Machinery Health Evaluation by Modal Force Identification. Available online: https://doi.org/10. 1080/17415977.2019.1644331. (accessed on 1 July 2019).

8. Głowacz, A.; Głowacz, Z. Recognition of rotor damages in a DC motor using acoustic signals. Bull. Pol. Acad. Sci. Tech. Sci. 2017, 65, 187-194. [CrossRef]

9. Głowacz, A.; Glowacz, W. Vibration-based fault diagnosis of commutator motor. Shock Vib. 2018, 2018, 7460419. [CrossRef] 
10. Stief, A.; Ottewill, J.; Baranowski, J.; Orkisz, M. A PCA and two-stage bayesian sensor fusion approach for diagnosing electrical and mechanical faults in induction motors. IEEE Trans. Ind. Electron. 2019, 66, 9510-9520. [CrossRef]

11. Wang, C.; Xing, Z.; Hou, F. Research on axis orbit of the journal bearing lubricated with oil and refrigerant mixtures in a twin-screw refrigeration compressor. Int. J. Refrig. 2018, 90,1-11. [CrossRef]

12. Liu, S.; Qu, L. A new field balancing method of rotor systems based on holospectrum and genetic algorithm. Appl. Soft Comput. 2008, 8, 446-455. [CrossRef]

13. Pang, X.; Yang, Z.; Yuan, J. Recognition of torque load for elastic support rotor system based on axis orbit. In Proceedings of the International Conference on Ubiquitous Robots \& Ambient Intelligence, Xi'an, China, 19-22 August 2016.

14. Meng, G.; Hahn, E.J. Dynamic response of a cracked rotor with some comments on crack detection. J. Eng. Gas Turbines Power 1997, 119, 447-455. [CrossRef]

15. Sinou, J.J.; Lees, A.W. A non-linear study of a cracked rotor. Eur. J. Mech. A Solids 2007, 26, 152-170. [CrossRef]

16. Cao, J.; Xue, S.; Lin, J. Nonlinear Dynamic Analysis of a Cracked Rotor-Bearing System with Fractional Order Damping. J. Comput. Nonlinear Dyn. 2012, 8, 031008. [CrossRef]

17. Nembhard, A.D.; Sinha, J.K.; Yunusa-Kaltungo, A. Experimental observations in the shaft orbits of relatively flexible machines with different rotor related faults. Measurement 2015, 75, 320-337. [CrossRef]

18. Guo, C.; Yan, J.; Yang, W. Crack detection for a Jeffcott rotor with a transverse crack: An experimental investigation. Mech. Syst. Signal Process. 2017, 83, 260-271. [CrossRef]

19. Xiang, L.; Zhang, Y.; Hu, A. Crack characteristic analysis of multi-fault rotor system based on whirl orbits. Nonlinear Dyn. 2019, 95, 2674-2690. [CrossRef]

20. Shudeifat, A.; Mohammad, A. New backward whirl phenomena in intact and cracked rotor systems. J. Sound Vib. 2019, 443, 124-138. [CrossRef]

21. Gubran, A.A.; Sinha, J.K. Shaft instantaneous angular speed for blade vibration in rotating machine. Mech. Syst. Signal Process. 2014, 44, 47-59. [CrossRef]

22. Mostafa, W.; Cousinard, O.; Boloares, F. Low speed bearings fault detection and size estimation using instantaneous angular speed. J. Vib. Control 2016, 22, 3413-3425. [CrossRef]

23. Zhao, M.; Jia, X.; Lin, J. Instantaneous speed jitter detection via encoder signal and its application for the diagnosis of planetary gearbox. Mech. Syst. Signal Process. 2018, 98, 16-31. [CrossRef]

24. Li, B.; Zhang, X. A new strategy of instantaneous angular speed extraction and its application to multistage gearbox fault diagnosis. J. Sound Vib. 2017, 396, 340-355. [CrossRef]

25. Li, B.; Zhang, X.; Wu, T. Measurement of Instantaneous Angular Displacement Fluctuation and its applications on gearbox fault detection. ISA Trans. 2018, 74, 245-260. [CrossRef] [PubMed]

26. Gomez, J.; Khelf, I.; Bourdon, A. Angular modeling of a rotating machine in non-stationary conditions: Application to monitoring bearing defects of wind turbines with instantaneous angular speed. Mech. Mach. Theory 2019, 136, 27-51. [CrossRef]

27. Wang, Y.; Tang, B.; Meng, L. Adaptive estimation of instantaneous angular speed for wind turbine planetary gearbox fault detection. IEEE Access 2019, 7, 49974-49984. [CrossRef]

28. Bourdon, A.; Chesné, S.; André, H. Reconstruction of angular speed variations in the angular domain to diagnose and quantify taper roller bearing outer race fault. Mech. Syst. Signal Process. 2019, 120, 1-15. [CrossRef]

29. Xie, J.; Cheng, W.; Zi, Y. Modified breathing mechanism model and phase waterfall plot diagnostic method for cracked rotors. J. Mech. Sci. Technol. 2018, 32, 2527-2530. [CrossRef]

30. Xie, J.; Zi, Y.; Cheng, W. Mechanism explanation and experimental verification of a new modulation frequency characteristic in a disturbed crack rotor. Nonlinear Dyn. 2019, 95, 597-616. [CrossRef]

(C) 2019 by the authors. Licensee MDPI, Basel, Switzerland. This article is an open access article distributed under the terms and conditions of the Creative Commons Attribution (CC BY) license (http://creativecommons.org/licenses/by/4.0/). 